\title{
Medication Use in Patients Presenting to a Rural and Remote Memory Clinic
}

\author{
Trevor A Steve, Andrew Kirk, Margaret Crossley, Debra Morgan, Carl D'Arcy, Jay Biem, \\ Dorothy Forbes, Norma Stewart
}

Can. J. Neurol. Sci. 2008; 35: 669-671

Cholinergic projection systems play a role in modulating cortical activity through activation of muscarinic receptors. Brain regions containing cholinergic neurons include the nucleus basalis of Meynert (NBM) and the medial septal nuclei (MSN), which send diffuse projections to cortex.$^{1-3}$ Brains of patients with Alzheimer's Disease (AD) exhibit loss of cholinergic neurons in the NBM and MSN. ${ }^{4}$ These findings have lent considerable support to the cholinergic hypothesis of cognitive dysfunction. ${ }^{5}$ Acetylcholinesterase inhibitors such as donepezil, ${ }^{6}$ rivastigmine $^{7}$ and galantamine ${ }^{8}$ are postulated to improve cognition by increasing cholinergic function.

Patients with AD may be more sensitive to the effects of anticholinergic drugs than are age-matched controls. ${ }^{9}$ In addition, drugs with anticholinergic activities are relatively contraindicated in the elderly even in the absence of dementia. ${ }^{10-12}$

A significant number of drugs without prominent anticholinergic effects have also been shown to contribute to cognitive impairment in elderly patients. ${ }^{13}$ Benzodiazepines, in particular, have been implicated as potentially problematic in older adults. ${ }^{10,11}$ Previous studies have suggested an association between benzodiazepine use and cognitive impairment. ${ }^{14,15}$ In addition, polypharmacy is of concern in the elderly due to the additive effects of medications.

This paper describes medication use in patients presenting to a multidisciplinary rural and remote memory clinic. Demographics of patients referred, patterns of medication use, and proportion of patients presenting on anticholinergic medications and benzodiazepines are discussed.

This study assesses the extent of anticholinergic medication use in $\mathrm{AD}$ patients versus patients without $\mathrm{AD}$, examines the Mini-Mental State Exam (MMSE) scores of patients on anticholinergic medications and not on anticholinergic medications, and compares the present findings with those in the published literature.

\section{METHODS}

Sixty-six consecutively assessed patients in a Rural and Remote Memory Clinic were included in the analysis. The initial assessment was used to determine the patient's age, MMSE, ${ }^{16}$ and diagnosis. At a pre-appointment telehealth visit, caregivers were asked to bring patients' medications to their clinic appointment. Drugs were then documented and organized by class.

Medications were assessed for their anticholinergic properties using published criteria. ${ }^{10-12,17-20}$ Benzodiazepine use was also documented. Ethics approval for this study was obtained from the University of Saskatchewan Behavioral Research Ethics Board.

\section{RESULTS}

The mean age was 74.1 years $(\mathrm{SD}=11.1)$ and mean MMSE score was 21.6 $(\mathrm{SD}=6.86)$. The most frequent diagnosis was probable Alzheimer's disease (57.1\%). Other common diagnoses were mild cognitive impairment $(10.7 \%)$, dementia with Lewy bodies $(7.1 \%)$, and vascular dementia $(5.4 \%)$. Other patients were diagnosed with frontotemporal dementia, bipolar affective disoder, depression, delirium, seasonal affective disorder, Huntington's disease, or frontal infarct.

The number of medications taken by patients is summarized in Table 1. Of the 66 patients included in this study, 89.4\% presented on two or more drugs while $6.1 \%$ were on no medications. The mean number of medications at first assessment was $4.80(\mathrm{SD}=3.66)$.

Patients presented to clinic on a variety of different medications, encompassing forty-eight different classes. Sixteen $(24 \%)$ of the patients in our study were taking anticholinergic medications; nine (14\%) were taking benzodiazepines, and twenty-one $(32 \%)$ were on either one anticholinergic, one benzodiazepine, or one of each. The anticholinergic medications patients were taking is summarized in Table 2.

Further analysis of the data indicates that of the 38 patients presenting to our clinic with a diagnosis of probable Alzheimer's Disease, $4(10.5 \%)$ were on anticholinergic medications. In contrast, of the 28 patients presenting to our clinic with a diagnosis of a condition other than probable Alzheimer's Disease, 12 (42.9\%) were on anticholinergic medications.

There was a statistically significant difference $(p=0.0074)$ between the MMSE scores of patients on anticholinergic medications or benzodiazepines versus patients not on these

From the University of Saskatchewan (TAS, AK, MC, DM, CD, NS), Saskatoon, Saskatchewan; McGill University (JB), Montreal, Quebec; University of Western Ontario (DF), London, Ontario.

Received January 5, 2007. Final Revisions Submitted May 27, 2008. Correspondence to: Andrew Kirk, Royal University Hospital, Dept of Medicine (Neurology), 103 Hospital Drive, Saskatoon, Saskatchewan, S7N 0W8. Canada. 
Table 1: Number of medications

\begin{tabular}{ll}
\hline Number of Medications & Patients (\%) \\
0 & $4(6 \%)$ \\
$\geq 1$ & $62(94 \%)$ \\
$\geq 2$ & $59(89 \%)$ \\
$\geq 3$ & $46(70 \%)$ \\
$\geq 4$ & $41(62 \%)$ \\
$\geq 5$ & $30(45 \%)$ \\
$\geq 6$ & $23(35 \%)$ \\
\hline
\end{tabular}

medications. There were $45(68.2 \%)$ patients in our study who were on no such medications. The mean MMSE score for this group was 20.02/30. There were $21(31.8 \%)$ patients in our study who were on anticholinergic medications and/or benzodiazepines. The mean MMSE score for this group was 25.00/30.

\section{Discussion}

Previous authors have found similar results to ours. One group found that $20.1 \%$ of medical inpatients were taking anticholinergic drugs. ${ }^{21}$ Another study reported that $33.0 \%$ of patients prescribed Donepezil, presumably for dementia, were also on an anticholinergic medication. ${ }^{18} \mathrm{~A}$ study of a large population of elderly outpatients found that $13.7 \%$ of the subjects were on anticholinergic drugs. ${ }^{12}$ A recent study of anticholinergic drug prescriptions indicated that $35.4 \%$ of patients receiving an acetylcholinesterase inhibitor also received an anticholinergic drug. ${ }^{19}$ Our figure of $24.2 \%$ shows a lower result in a rural and remote population with cognitve symptoms.

It is worth noting that our value of $24.2 \%$ is lower than the percentage of patients on anticholinergic medications in some other studies. It is possible that referring physicians are now more aware of the issues around use of anticholinergic drugs. It is also interesting to note that the proportion of patients with a diagnosis of probable Alzheimer's Disease who were on anticholinergic medications is considerably lower than the same proportion in patients with other diagnoses. One possible explanation for this trend is that physicians avoid prescribing anticholinergic medications to patients with Alzheimer's Disease.

The data also indicate a difference between MMSE scores in the patients taking anticholinergics and/or benzodiazepines as compared to patients not taking these medications. The MMSE scores for patients taking these medications were significantly higher than the MMSE scores for patients not taking these medications. This may indicate that once patients are clearly demented, they are taken off these medications.

\section{Table 2: Anticholinergic medications}

\begin{tabular}{lll}
\hline Medication & $\begin{array}{l}\text { Number of } \\
\text { Patients }\end{array}$ & Type of Medication \\
Amitryptiline & 2 & Tricyclic Antidepressant \\
Benztropine & 1 & Antiparkinsonian Medication \\
Diphenhydramine & 1 & H1-Antihistamine \\
Doxepin & 1 & Tricyclic Antidepressant \\
Olanzapine & 1 & Antipsychotic \\
Oxybutinin & 1 & Bladder Medication \\
Paroxetine & 2 & SSRI \\
Ranitidine & 4 & H2-Antihistamine \\
Tolterodine & 3 & Bladder Medication \\
\hline
\end{tabular}

It can be ascertained from this study that many patients present with memory complaints while taking a substantial number of medications. These often include drugs that might contribute to cognitive symptoms such as anticholinergic drugs and benzodiazepines.

\section{REFERENCES}

1. Mesulam MM. The cholinergic innervation of the human cerebral cortex. Prog Brain Res. 2004;145:67-78.

2. Nathanson NM. Regulation of muscarinic acetylcholine receptor expression and function. Prog Brain Res. 1996;109:166-8.

3. Everitt BJ, Robbins TW. Central cholinergic systems and Cognition, 1997. Annu Rev Psychol. 1997;48:649-84.

4. Davies P, Maloney AJ. Selective loss of central cholinergic neurons in Alzheimer's disease. Lancet. 1976;2:1403.

5. Bartus RT, Dean RL 3rd, Beer B, Lippa AS. The cholinergic hypothesis of geriatric memory dysfunction. Science. 1982; 217:408-14.

6. Rogers SL, Doody RS, Mohs R, Friedhoff LT. Donepezil improves cognition and global function in alzheimer disease: a 15-week, double-blind, placebo-controlled study. Arch Intern Med. 1998; 158:1021-31.

7. Rosler M, Anand R, Cicin-Sain A, Gauthier S, Agid Y, Dal-Bianco $\mathrm{P}$, et al. Efficacy and safety of rivastigmine in patients with Alzheimer's disease: international randomised controlled trial. Brit Med J. 1999;318:633-40.

8. Tariot PN, Solomon PR, Morris JC, Kershaw P, Lilienfeld S, Ding $\mathrm{C}$, et al. A 5-month, randomized, placebo-controlled trial of galantamine in AD. Neurology. 2000;54:2269-76.

9. Sunderland T, Tariot PN, Cohen RM, Weingartner H, Mueller EA 3rd, Murphy DL. Anticholinergic sensitivity in patients with dementia of the Alzheimer type and age-matched controls: a dose-response study. Arch Gen Psychiat. 1987;44:418-26.

10. Beers MH. Explicit criteria for determining potentially inappropriate medication use by the elderly: an update. Arch Int Med. 1997;157:1531-6.

11. Fick DM, Cooper JW, Wade WE, Waller JL, Maclean JR, Beers $\mathrm{MH}$. Updating the beers criteria for potentially inappropriate medication use in older adults: results of a US consensus panel of experts. Arch Int Med. 2003;163:2716-24. 
12. Lechevallier-Michel N, Molimard M, Dartigues J, Fabrigoule C, Fourrier-Reglat A. Drugs with anticholinergic properties and cognitive performance in the elderly: results from the PAQUID Study. Brit J Pharmacol. 2005;59:143-51.

13. Moore AR, O'Keefe ST. Drug-induced cognitive impairment in the elderly. Drug Aging. 1999;15:15-28.

14. Folstein MF, Folstein SE, McHugh PR. "Mini-mental state". A practical method for grading cognitive state of patients for the clinician. J Psychiat Res. 1975;12:189-98.

15. Verdoux H, Lagnaoui R, Begaud B. Is benzodiazepine use a risk factor for cognitive decline and dementia? A literature review of epidemiological studies. Psychol Med. 2005;35:307-15.

16. Lagnaoui R, Begaud B, Moore N, Chaslerie A, Fourrier A, Letenneur L, et al. Benzodiazepine use and risk of dementia: a nested case-control study. J Clin Epidemiol. 2002;55:314-18.

17. Foy A, O'Connell D, Henry D, Kelly J, Cocking S, Halliday J. Benzodiazepine use as a cause of cognitive impairment in elderly hospital inpatients. J Gerontol. 1995;50:M99-106.
18. Roe CM, Anderson MJ, Spivack B. Use of Anticholinergic medications by older adults with dementia. J Am Ger Soc. 2002; 50:836-42.

19. Carrahan RM, Lund BC, Perry PJ, Chrischilles EA. The concurrent use of anticholinergics and cholinesterase inhibitors: Rare event or common practice? J Am Ger Soc. 2004;52:2082-7.

20. Fujishiro J, Imanishi T, Onozawa K, Tsushima M. Comparison of the anticholinergic effects of the serotonergic antidepressants, paroxetine, fluvoxamine, and clomipramine. Eur J Pharmacol. 2002;454:183-8.

21. Han L, McCusker J, Cole M, Abrahamowicz M, Primeau F, Elie M. Use of medications with anticholinergic effect predicts clinical severity of delirium symptoms in older medical inpatients. Arch Int Med. 2001;161:1099-105. 